JURNAL ILMU KeSEHATAN BHAKTI HUSADA:

HEALTH SCIENCES JOURNAL, VOL. 11 No. 02, DESEMBER 2020

DOI: $10.34305 /$ jikbh.v11i2.199
Ciptaan disebarluaskan di bawah

Lisensi Creative Commons Atribusi-

NonKomersial-BerbagiSerupa 4.0

Internasional.

\title{
HUBUNGAN ANTARA PENGETAHUAN DAN SIKAP IBU DENGAN STATUS GIZI PADA BALITA DI WILAYAH UPTD PUSKESMAS CIDAHU KECAMATAN CIDAHU KABUPATEN KUNINGAN
}

\author{
Indrayani, Linda Cahyani Rusmiadi, Anggit Kartikasari
}

STIKes Kuningan

indriadit15@gmail.com

\begin{abstract}
Abstrak
Balita merupakan kelompok usia yang paling menderita akibat kurang gizi dan jumlahnya dalam populasi cukup besar. Kuningan pada tahun 2018 ditemukan 3.551 kasus dengan gizi kurang (4,95\%) dengan urutan tertinggi berada di Kecamatan Cidahu didapatkan 273 kasus gizi kurang $(12,10 \%)$. Beberapa faktor yang mempengaruhi status gizi balita diantaranya pengetahuan dan sikap. Tujuan penelitian untuk mengetahui hubungan antara pengetahuan dan sikap ibu tentang gizi dengan status gizi pada balita di wilayah UPTD Puskesmas Cidahu Kecamatan Cidahu Kabupaten Kuningan tahun 2020.

Metode penelitian yang digunakan adalah penelitian analitik kuantitatif dengan rancangan cross sectional dengan menggunakan data primer, jumlah sampel sebanyak 96 responden, teknik pengambilan sampel proportional stratified random sampling yaitu ibu balita yang berada di wilayah UPTD Puskesmas Cidahu Kecamatan Cidahu Kabupaten Kuningan, analisa data menggunakan spearman rank.

Hasil analisis univariat sebagian besar balita memiliki status gizi baik yaitu sebesar $83,3 \%$, sebagian ibu balita memiliki pengetahuan baik yaitu sebesar $40,6 \%$ dan sebagian besar memiliki sikap positif yaitu sebesar $76,0 \%$. Hasil analisis bivariat terdapat hubungan antara pengetahuan ibu tentang gizi $(\mathrm{p}=0,006)$ dan sikap $(\mathrm{p}=0,003)$ dengan status gizi pada balita.

Hasil penelitian pengetahuan dan sikap ibu tentang gizi berhubungan dengan status gizi pada balita. Diharapkan Ibu balita dapat meningkatkan pengetahuannya tentang asupan makan yang baik dengan menu gizi seimbang agar dapat meningkatkan dan mempertahankan status gizi anak balitanya.
\end{abstract}

Kata kunci $\quad$ :Pengetahuan, Sikap, Status Gizi Balita 
JURNAL ILMU KeSEHATAN BHAKTI HUSADA:

HEALTH SCIENCES JouRnal, Vol. 11 No. 02, DESEMBER 2020

DOI: $\underline{10.34305 / j i k b h . v 11 i 2.199}$
Ciptaan disebarluaskan di bawah

Lisensi Creative Commons Atribusi-

NonKomersial-BerbagiSerupa 4.0 Internasional.

\section{Pendahuluan}

Kementerian Kesehatan Republik Indonesia, (2018) mengatakan bahwa kesehatan adalah hak asasi manusia dan sekaligus merupakan investasi sumber daya manusia. Kualitas sumber daya manusia dimasa yang akan datang sangat dipengaruhi oleh status gizi. Kekurangan gizi, menimbulkan masalah kesehatan (morbiditas, mortalitas dan disabilitas) dan menurunkan kualitas sumber daya manusia (SDM) suatu bangsa.

Balita menurut Par'I, (2016:2) merupakan kelompok usia yang paling menderita akibat kurang gizi dan jumlahnya dalam populasi cukup besar. Linda \& Hamal, (2016:34) menambahkan bahwa kurang gizi pada balita dapat berakibat gagal tumbuh kembang serta meningkatkan kesakitan dan kematian. Gizi kurang merupakan status gizi yang didasarkan pada indeks berat badan menurut umur $(\mathrm{BB} / \mathrm{U})$.

Menurut Stastika, (2018) dalam sebuah riset menghasilkan Global Hunger Index (GHI) untuk mengukur tingkat kelaparan dan kekurangan gizi secara global didapatkan 8 negara mengalami dampak kelaparan dan kekurangan gizi diantaranya Republik Afrika Tengah (46,1\%), Chad (44,3\%), Zambia (39\%), Haiti (36,9\%), Madagaskar (35,4\%), Sierra
Leone (35\%), Yaman (35\%) dan Afganistan $(34,8 \%)$. Persentase anak yang mengalami gizi kurang pada usia 0 sampai 4 bulan.

Informasi dari Kementerian

Kesehatan Republik Indonesia, (2018:143) Pemantauan Status Gizi (PSG) tahun 2017 yang diselenggarakan oleh Kementerian Kesehatan menyatakan bahwa persentase gizi kurang adalah 14\%. Provinsi dengan persentase tertinggi gizi kurang pada balita usia 0-59 bulan tahun 2017 adalah Nusa Tenggara Timur, sedangkan provinsi dengan persentase terendah adalah Bali. Sementara itu Provinsi Jawa Barat persentase gizi kurang sebesar 12,20\%. Sementara itu, menurut Laporan Tahunan Dinas Kesehatan Kabupaten Kuningan pada tahun 2018 ditemukan 3.551 kasus dengan gizi kurang $(4,95 \%)$ dengan urutan tertinggi berada di Kecamatan Cidahu didapatkan 273 kasus gizi kurang (12,10\%) (Dinkes Kab Kuningan, 2019).

Apabila balita tersebut mengalami gizi kurang atau buruk dalam jangka waktu yang lama, maka akan menimbulkan terjadinya stunting atau tidak sesuainya tinggi badan sesuai umur, jika permasalahan ini terus berlanjut diproyeksikan bahwa pada tahun 2025 terdapat 127 juta anak berusia dibawah lima tahun akan mengalami stunting. Pada tahun 
JURNAL ILMU KESEHATAN BHAKTI HUSADA:

HEALTH SCIENCES JouRnal, Vol. 11 No. 02, DESEMBER 2020

DOI: $\underline{10.34305 / j i k b h . v 11 i 2.199}$
Ciptaan disebarluaskan di bawah

Lisensi Creative Commons Atribusi-

NonKomersial-BerbagiSerupa 4.0

Internasional.
2017 didapatkan 22,2\% atau kurang lebih 150,8 juta balita yang berada di dunia mengalami stunting. Menurut laporan The Lancet's, di dunia anak berusia kurang dari lima tahun (balita) yang stunting dengan luas mayoritas di South-Central Asia dan sub-Sahara Afrika. 28,5\% dan di seluruh negara berkembang sebesar $31,2 \%$. Benua Asia prevalensi balita stunting sebesar $30,6 \%$, kejadian ini jauh lebih tinggi dibanding dengan prevalensi balita stunting di Amerika latin dan Karibia, yaitu sebesar $14,8 \%$. Prevalensi balita stunting di Asia tenggara adalah 29,4 \%, lebih tinggi dibandingkan dengan Asia Timur (14,4\%) dan Asia Barat (20,9 \%) (Say et al., 2018).

Merujuk pada standar WHO, batas maksimal angka stunting yaitu $20 \%$ atau seperlima dari jumlah total anak balita. Organisasi Kesehatan Dunia (WHO) menempatkan Indonesia sebagai negara ketiga dengan angka prevalensi stunting tertinggi kedua di Asia pada 2017. Angkanya mencapai $36,4 \%$, sementara itu tertinggi pertama yaitu Laos mencapai 43,8\%. Namun, pada 2018, menurut data Riset Kesehatan Dasar (Riskesdas), angkanya terus menurun hingga 23,6\%. Dari data yang sama, diketahui pula stunting pada balita di Indonesia pun turun menjadi $30,8 \%$, adapun pada Riskesdas
2018, stunting balita mencapai 37,2\% (Novianto H., 2019).

Selanjutnya proporsi status gizi sangat pendek dan pendek pada anak balita menurut Buku Saku Pemantauan Status Gizi dengan normal mencapai 70,4\%, proporsi pendek mencapai 19,8\% dan sangat pendek mencapai $9,8 \%$. Sementara itu Provinsi Jawa Barat dengan normal mencapai $70,8 \%$, proporsi pendek mencapai $20,8 \%$ dan sangat pendek mencapai $8,8 \%$ (Kementerian Kesehatan Republik Indonesia, 2018:39).

Menurut Gubernur Jawa Barat, Ridwan Kamil menyebutkan ada 13 daerah dengan penderita terbanyak. Ironisnya Kabupaten Kuningan menjadi salah satu penyumbang penderita stunting terbanyak di Jawa Barat yaitu sebesar $42 \%$. Kabupaten Kuningan sendiri ada 10 desa yang anaknya mengalami stunting. Desa Cidahu tidak termasuk dari 10 desa tersebut, akan tetapi berdasarkan data dari Desa Cidahu ditemukan 7,28\% anak yang mengalami stunting (Melinda A, 2020).

Menurut Adriani \& Wirjatmadi, (2014) beberapa faktor yang dapat mempengaruhi asupan gizi antara lain faktor langsung diantaranya kurangnya asupan gizi dan makanan serta penyakit infeksi, adapun faktor tidak langsung antara 
JURNAL ILMU KeSEHATAN BHAKTI HUSADA:

HEALTH SCIENCES JouRnal, Vol. 11 No. 02, DESEMBER 2020

DOI: $\underline{10.34305 / j i k b h . v 11 i 2.199}$
Ciptaan disebarluaskan di bawah

Lisensi Creative Commons Atribusi-

NonKomersial-BerbagiSerupa 4.0 Internasional. lain pengetahuan dan sikap orang tua khususnya ibu tentang gizi, pendapatan keluarga, budaya, kebersihan lingkungan dan fasilitas kesehatan. Adapun faktor yang sangat berpengaruh terhadap status gizi balita adalah faktor yang berasal dari ibu adalah pengetahuan dan sikap. Sesuai dengan Peraturan Menteri Kesehatan Nomor 23 Tahun 2014 tentang Upaya Perbaikan Gizi, dalam menerapkan gizi seimbang setiap keluarga harus mampu mengenal, mencegah, dan mengatasi masalah gizi setiap anggota keluarganya (Kementerian Kesehatan Republik Indonesia, 2018:143).

Menurut Budiman et al., (2013:27) pemberian asupan makanan yang baik pada balita dibutuhkan pengetahuan yang baik pula. Tingkat pengetahuan setiap orang tentang gizi tidak sama. Hal ini terjadi karena berbagai faktor seperti pendidikan, informasi, sosial budaya, lingkungan, pengalaman dan usia. sesuai dengan pendapat Dewi \& Rusjiyanto, (2018), pengetahuan gizi ibu yang rendah dapat menghambat usaha perbaikan gizi yang baik pada keluarga.

Romdiyatin, (2016:72) menjelaskan bahwa kurangnya pengetahuan tentang bahan makanan dapat menyebabkan salahnya pemilihan makanan dan rendahnya pengetahuan gizi akan menyebabkan sikap masa bodoh terhadap makan tertentu. Menurut Mubarak et al., (2017:4) sikap merupakan reaksi atau respon seseorang terhadap suatu stimulus atau objek. Sikap dalam kehidupan sehari- hari merupakan reaksi yang bersifat emosional terhadap stimulus sosial.

Puskesmas Cidahu terdiri dari sebelas Desa diantaranya Desa Cihideunggirang, Desa Cihideung Hilir, Desa Nanggela, Desa Cidahu, Desa Kertawinangun, Desa Datar, Desa Bunder, Desa Cieurih, Desa Cibulan, Desa Legok, Desa Cikeusik dan Desa Jatimulya. Berdasarkan data penimbangan pada Februari tahun 2019 dari sebelas Desa tersebut menurut indikator $\mathrm{BB} / \mathrm{U}$ dari 2828 balita terdapat 285 balita dengan gizi kurang $(12,20 \%)$.

Survei data awal yang peneliti lakukan bulan Februari tahun 2020 pada 10 ibu yang melakukan penimbangan anak balitanya ke Posyandu yang berada di Desa Cidahu yang merupakan salah satu desa yang berada di wilayah Puskesmas Cidahu, didapatkan hasil 6 balita mengalami gizi kurang, sementara 4 balita mengalami gizi baik. Berdasarkan informasi dari 6 ibu yang mempunyai anak balita dengan gizi kurang mengatakan bahwa selama ini mereka 
JURNAL ILMU KeSEHATAN BHAKTI HUSADA:

HEALTH SCIENCES JOURNAL, VOL. 11 No. 02, DESEMBER 2020

DOI: $\underline{10.34305 / j i k b h . v 11 i 2.199}$
Ciptaan disebarluaskan di bawah

Lisensi Creative Commons Atribusi-

NonKomersial-BerbagiSerupa 4.0 Internasional. memberi makan pada anaknya seadanya, sesuai dengan keinginan anaknya saja tanpa memperhatikan menu gizi seimbang.

\section{Materi dan Metode}

Penelitian ini merupakan jenis penelitian analitik kuantitatif dengan menggunakan rancangan cross sectional. Teknik pengambilan sampel menggunakan proportional stratified random sampling. Instrumen penelitian yang digunakan untuk mengukur tentang pengetahuan dan sikap Ibu tentang gizi balita menggunakan kuesioner. Kuesioner tentang pengetahuan Ibu menggunakan skala Guttman dengan jumlah 20 soal (14 pernyataan positif dan 6 pernyataan negatif), sedangkan untuk mengukur sikap Ibu tentang gizi anak balita menggunakan skala Likert dengan jumlah pertanyaan 11 soal ( 7 pernyataan positif dan
4 pernyataan negatif) berupa penilaian Ibu terhadap status gizi anak balita, cara pemberian makan pada balita dan pertumbuhan balita. Berhubung adanya pandemi covid-19, maka peneliti dalam pengumpulan data primer, dilakukan dengan bantuan google form dan dibagikan kepada responden melalui aplikasi whatsApp. Sebelum melakukan pengisian, peneliti menginformasikan terlebih dahulu kepada responden terkait kesediaannya menjadi responden dalam penelitian ini.

\section{Hasil dan Pembahasan}

\section{Status Gizi Balita}

Dari hasil penelitian menunjukkan bahwa dari 96 balita sebagian besar memiliki status gizi baik yaitu sebesar 80 responden $(83,3 \%)$.

Tabel 1. Hasil Analisis Deskriptif Status Gizi Balita

\begin{tabular}{lll}
\hline Status Gizi & frekuensi (f) & Persentase (\%) \\
\hline Gizi Baik & 80 & 83,3 \\
\hline Gizi Kurang & 16 & 16,7 \\
\hline Jumlah & 96 & 100 \\
\hline
\end{tabular}

\section{Pengetahuan Ibu}

Dari hasil penelitian menunjukkan bahwa dari 96 ibu balita sebagian memiliki pengetahuan baik yaitu sebesar 39 orang (40,6\%). Menurut Suhardjo, (2013:21) pengetahuan gizi yang baik akan menyebabkan seseorang mampu menyusun menu yang baik untuk dikonsumsi. Semakin banyak pengetahuan gizi seseorang, maka ia akan semakin memperhitungkan jenis dan jumlah makanan yang diperolehnya untuk 
JURNAL ILMU KeSEHATAN BHAKTI HUSADA:

HEALTH SCIENCES JouRnal, Vol. 11 No. 02, DESEMBER 2020

DOI: $\underline{10.34305 / j i k b h . v 11 i 2.199}$
Ciptaan disebarluaskan di bawah

Lisensi Creative Commons Atribusi-

NonKomersial-BerbagiSerupa 4.0 Internasional. dikonsumsi. Notoatmodjo, (2017:58) menambahkan bahwa pengetahuan atau kognitif merupakan domain yang sangat penting dalam membentuk tindakan seseorang. Berdasarkan pengalaman dan penelitian terbukti bahwa perilaku yang didasari oleh pengetahuan lebih langgeng dari pada perilaku yang tidak didasari oleh pengetahuan. Ibu yang memiliki pengetahuan baik disebabkan oleh pendidikan yang Ibu tempuh, hal ini sesuai dengan hasil penelitian ditemukan bahwa sebagian besar ibu dengan pendidikan SMA bahkan ada ibu yang memiliki pendidikan tinggi sehingga memiliki kemudahan dalam menerima informasi.

Tabel 2. Hasil Analisis Deskriptif Pengetahuan Ibu

\begin{tabular}{lll}
\hline Pengetahuan Ibu & frekuensi (f) & Persentase (\%) \\
\hline Baik & 39 & 40,6 \\
\hline Cukup & 36 & 37,5 \\
\hline Kurang & 21 & 21,9 \\
\hline Jumlah & 96 & 100 \\
\hline
\end{tabular}

\section{Sikap Ibu}

Dari hasil penelitian menunjukkan bahwa Dari 96 ibu balita sebagian besar memiliki sikap positif yaitu sebesar 73 orang (76,0\%). Menurut Behrman, Kligman, Arvin, \& Wahab, (2016:22) faktor yang mempengaruhi pembentukan sikap diantaranya pengalaman pribadi dan pengetahuan, kebudayaan, orang yang dianggap penting, media massa dan emosi dalam diri.

Peneliti berasumsi banyaknya Ibu memiliki sikap positif, hal ini disebabkan oleh karena adanya pengetahuan ibu yang baik khususnya tentang gizi balita. Hal ini sesuai dengan hasil kuesioner ditemukan bahwa Ibu memiliki sikap positif tentang bagaimana cara menyuapi anak yang baik salah satunya yaitu memberikan makanan dengan aneka ragam agar gizinya tercukupi. Disamping itu sebelum memberikan makan kepada anak balitanya ibu akan mencuci tangan terlebih dahulu dengan menggunakan sabun dan air yang mengalir. Berdasarkan hasil kuesioner banyak ibu yang bersikap positif juga disaat berat badan anak balitanya turun pada bulan lalu dan berada pada pita merah maka ibu akan segera melakukan konsultasi kepada petugas kesehatan. 
JURNAL ILMU KeSEHATAN BHAKTI HUSADA:

HEALTH SCIENCES JOURNAL, VOL. 11 No. 02, DESEMBER 2020

DOI: $10.34305 / j i k b h . v 11$ i2.199
Ciptaan disebarluaskan di bawah

Lisensi Creative Commons Atribusi-

NonKomersial-BerbagiSerupa 4.0 Internasional.

Tabel 3. Hasil Analisis Deskriptif Sikap Ibu

\begin{tabular}{lll}
\hline Sikap Ibu & frekuensi (f) & Persentase (\%) \\
\hline Positif & 73 & 76,0 \\
\hline Negatif & 23 & 24,0 \\
\hline Jumlah & 96 & 100
\end{tabular}

Hubungan antara Pengetahuan Ibu dengan Status Gizi pada Balita

Hasil penelitian menunjukkan bahwa dari 39 ibu balita yang memiliki pengetahuan baik secara keseluruhan memiliki status gizi baik (100,0\%), dari 39 responden yang memiliki pengetahuan cukup, sebagian besar memiliki status gizi baik yaitu sebanyak 32 orang $(88,9 \%)$ dan dari 21 responden yang berpengetahuan kurang, sebagian besar memiliki status gizi kurang yaitu sebanyak 12 orang $(57,1 \%)$. Hasil uji korelasi rank spearman didapatkan nilai $\mathrm{p}=0,006<0,05$ yang berarti terdapat korelasi yang bermakna antara pengetahuan ibu dengan status gizi pada balita. Nilai 0,277 merupakan korelasi lemah dengan arah positif, artinya semakin baik pengetahuan ibunya maka semakin baik status gizi balitanya.

Sesuai dengan hasil penelitian Susilowati \& Himawati, (2017), dalam penelitiannya tentang "Hubungan Tingkat Pengetahuan Ibu tentang Gizi Balita dengan Status Gizi Balita di Wilayah Kerja Puskesmas Gajah 1 Demak" diperoleh hasil signifikansi $\mathrm{p}$ value $=0,006$, karena $\mathrm{p}$ value $<$ 0,05 maka secara statistik ada hubungan yang signifikan antara tingkat pengetahuan ibu tentang gizi balita dengan status gizi balita.

Peneliti berasumsi adanya hubungan pengetahuan ibu dengan status gizi balita, hal ini disebabkan oleh karena ibu yang memiliki pengetahuan baik akan mengetahui asupan makanan apa yang boleh dikonsumsi pada anak balitanya agar kebutuhan gizinya terpenuhi, sehingga ibu yang memiliki pengetahuan baik akan berupaya memberikan makan pada anak balitanya bukan sekedar karena suka akan tetapi dilihat berdasarkan kandungan gizi dalam makanan tersebut. Kondisi tersebut menjadikan status gizi balita menjadi baik. Pengetahuan ibu yang baik disebabkan oleh karena pendidikan ibu yang tinggi sehingga mudah dalam menyerap dan memahami informasi khususnya pengetahuan gizi yang mereka peroleh sehingga ibu dapat lebih tanggap jika ditemukan adanya masalah pada anak balitanya dan dapat segera mengambil tindakan dengan cara cara E-ISSN 2623-1204 P-ISSN 2252-9462 | 230 
JURNAL ILMU KESEHATAN BHAKTI HUSADA:

HEALTH SCIENCES JOURNAL, VOL. 11 No. 02, DESEMBER 2020

DOI: $\underline{10.34305 / j i k b h . v 11 i 2.199}$
Ciptaan disebarluaskan di bawah

Lisensi Creative Commons Atribusi-

NonKomersial-BerbagiSerupa 4.0 Internasional melakukan konsultasi ke tenaga kesehatan maupun memberikan makanan dengan menu gizi seimbang.

Berbeda dengan ibu yang memiliki pengetahuan kurang ditemukan balita dengan status gizi kurang, hal ini disebabkan oleh karena kurangnya informasi yang Ibu dapatkan mengenai bagaimana cara merawat anak balitanya dengan baik dan benar khususnya dalam pemenuhan asupan makanan pada anak balitanya menjadikan ibu acuh tak acuh terhadap kondisi anaknya sehingga menjadikan status gizi anak menjadi kurang, karena kurangnya perhatian dari ibu yang disebabkan oleh karena kurangnya pengetahuan yang dimiliki oleh ibu. Agar dapat meningkatkan status gizi pada anak balitanya, sebaiknya ibu dapat meningkatkan pengetahuannya dengan cara mencari informasi dan aktif melakukan konsultasi dengan tenaga kesehatan agar ibu mengetahui pola makan yang baik pada anaknya.

Tabel 4. Hasil Uji Hubungan antara Pengetahuan Ibu dengan Status Gizi pada Balita

\begin{tabular}{|c|c|c|c|c|c|c|c|c|}
\hline \multirow{3}{*}{$\begin{array}{l}\text { Pengetah } \\
\text { uan Ibu }\end{array}$} & \multicolumn{4}{|c|}{ Status Gizi } & \multirow{2}{*}{\multicolumn{2}{|c|}{ Total }} & \multirow{3}{*}{$\mathrm{p}$-value } & \multirow{2}{*}{ Nilai r } \\
\hline & \multicolumn{2}{|c|}{ Gizi Baik } & \multicolumn{2}{|c|}{ Gizi Kurang } & & & & \\
\hline & $\mathrm{F}$ & $(\%)$ & $\mathrm{f}$ & $(\%)$ & $\mathrm{N}$ & $(\%)$ & & \multirow{4}{*}{0,277} \\
\hline Baik & 39 & 100,0 & 0 & 0,0 & 39 & 100 & \multirow{3}{*}{0,006} & \\
\hline Cukup & 32 & 88,9 & 4 & 11,1 & 36 & 100 & & \\
\hline Kurang & 9 & 42,9 & 12 & 57,1 & 21 & 100 & & \\
\hline
\end{tabular}

Hubungan antara Sikap Ibu dengan dengan status gizi pada balita. Nilai 0,300

\section{Status Gizi pada Balita}

Hasil penelitian menunjukkan

bahwa dari 73 responden yang memiliki sikap positif, sebagian besar memiliki status gizi baik yaitu sebanyak 69 responden $(94,5 \%)$ dan dari 23 ibu yang memiliki sikap negatif, sebagian besar status gizinya kurang yaitu sebanyak 12 orang $(52,2 \%)$. Hasil uji korelasi rank spearman didapatkan nilai $\mathrm{p}=0,003<0,05$ yang berarti terdapat korelasi yang bermakna antara sikap ibu merupakan korelasi lemah dengan arah positif, artinya semakin positif sikap ibunya maka semakin baik status gizi balitanya.

Sesuai dengan hasil penelitian Rahmatillah, (2018) menunjukkan hasil perhitungan uji statistik hubungan sikap dengan status gizi balita yaitu terdapat hubungan yang bermakna dengan $\mathrm{p}=0,001$ artinya terdapat hubungan antara sikap dengan status gizi balita. Penelitian senada dilakukan oleh Syarifah, L., Mardjan, \& 
JURNAL ILMU KeSEHATAN BHAKTI HUSADA:

HEALTH SCIENCES JOURNAL, VOL. 11 No. 02, DESEMBER 2020

DOI: $\underline{10.34305 / j i k b h . v 11 i 2.199}$
Ciptaan disebarluaskan di bawah

Lisensi Creative Commons Atribusi-

NonKomersial-BerbagiSerupa 4.0 Internasional.
Budiastutik, (2014) hasil uji statistik ChiSquare diperoleh nilai $\mathrm{p}$ value $=0,024<\alpha$ $(0,05)$, maka Ho ditolak (Ha diterima), artinya ada hubungan yang bermakna antara sikap ibu dengan kejadian gizi kurang pada balita di Wilayah Kecamatan Pontianak Kota.

Peneliti berasumsi sikap ibu berhubungan dengan status gizi balita, hal ini disebabkan oleh adanya kemampuan ibu dalam memilih makanan yang baik untuk anaknya, disamping itu itu disebabkan oleh adanya kepedulian ibu dalam merawat anaknya dengan baik dan benar. Banyaknya ibu yang memiliki sikap positif disebabkan oleh karena usia ibu yang sudah dewasa sehingga menimbulkan adanya kemampuan ibu dalam merawat anak balitanya dengan baik dan benar. Faktor lainnya disebabkan oleh adanya pengalaman pribadi dan adanya pengetahuan dimana sebelumnya ibu sudah memiliki kemampuan dalam merawat anak yang sebelumnya, sehingga pada anak yang sekarang yang Ibu sudah tidak canggung lagi dalam merawatnya.

Adapun pada ibu dengan sikap negatif kecenderungan status gizi anak berada pada kategori kurang hal ini disebabkan oleh karena kurangnya pengalaman dalam merawat anak balitanya, sehingga ibu memiliki sikap negatif dan acuh tak acuh dalam merawat anak balitanya. Agar dapat merubah sikap ibu yang negatif menjadi positif dalam merawat anak balitanya sebaiknya diperlukan adanya bimbingan tentang cara Bagaimana merawat anak dengan baik dan benar khusus mengenai asupan gizi yang baik agar status gizi anak balitanya menjadi baik. Jika dilihat hubungan antara pengetahuan dan sikap memiliki kekuatan yang lemah, hal ini disebabkan oleh masih ada faktor lain yang mempengaruhi terjadinya status gizi salah satunya yaitu kondisi ekonomi dan pendapatan keluarga. Untuk itu agar dapat meningkatkan pendapatan keluarga alangkah baiknya jika keluarga tersebut diberikan lahan pekerjaan yang bisa dikerjakan ibu dirumah sehingga selain memiliki kemampuan dalam meningkatkan pendapatan keluarga, ibu juga dapat mengurus anaknya dengan baik.

\section{Tabel 5. Hasil Uji Hubungan antara Sikap Ibu dengan Status Gizi pada Balita}

\begin{tabular}{|c|c|c|c|c|c|c|c|c|}
\hline \multirow{3}{*}{$\begin{array}{l}\text { Sikap } \\
\text { Ibu }\end{array}$} & \multicolumn{4}{|c|}{ Status Gizi } & \multirow{2}{*}{\multicolumn{2}{|c|}{ Total }} & \multirow{2}{*}{ p-value } & \multirow{2}{*}{ Nilai $r$} \\
\hline & \multicolumn{2}{|c|}{ Gizi Baik } & \multicolumn{2}{|c|}{ Gizi Kurang } & & & & \\
\hline & $\mathrm{f}$ & $(\%)$ & $\mathrm{f}$ & $(\%)$ & $\mathrm{n}$ & $(\%)$ & & \\
\hline Positif & 69 & 94,5 & 4 & 5,5 & 73 & 100 & 0,003 & 0,300 \\
\hline Negatif & 11 & 47,8 & 12 & 52,2 & 23 & 100 & & \\
\hline
\end{tabular}


JURNAL ILMU KeSEHATAN BHAKTI HUSADA:

HEALTH SCIENCES JOURNAL, VOL. 11 No. 02, DESEMBER 2020

DOI: $\underline{10.34305 / j i k b h . v 11 i 2.199}$

\section{Kesimpulan dan Saran}

\section{Kesimpulan}

Berdasarkan hasil penelitian bahwa sebagian besar balita memiliki status gizi baik yaitu sebesar $83,3 \%$.

Berdasarkan hasil penelitian bahwa sebagian ibu balita memiliki pengetahuan baik yaitu sebesar $40,6 \%$.

Berdasarkan hasil penelitian bahwa sebagian besar ibu balita memiliki sikap positif yaitu sebesar 76,0\%.

Terdapat hubungan antara pengetahuan ibu tentang gizi dengan status gizi pada balita di Wilayah UPTD Puskesmas Cidahu Kecamatan Cidahu Kabupaten Kuningan dengan nilai $\mathrm{p}=$ 0,006 .

Terdapat hubungan antara sikap ibu tentang gizi dengan status gizi pada balita di Wilayah UPTD Puskesmas Cidahu Kecamatan Cidahu Kabupaten Kuningan dengan nilai $\mathrm{p}=0,003$.

\section{Saran}

\section{Bagi Ibu Balita}

Diharapkan Ibu balita dapat meningkatkan pengetahuannya tentang asupan makan yang baik dengan menu gizi seimbang agar dapat meningkatkan dan mempertahankan status gizi anak balitanya yang dapat mempengaruhi pertumbuhan dan perkembangan anak balitanya.
Ciptaan disebarluaskan di bawah Lisensi Creative Commons Atribusi-

NonKomersial-BerbagiSerupa 4.0 Internasional

\section{Bagi Tenaga Kesehatan}

Hasil penelitian ini diharapkan tenaga kesehatan khususnya bidan dapat membantu meningkatkan Pengetahuan ibu dan merubah sikap ibu dalam memberikan asupan makanan pada anak balitanya dengan cara memberikan penyuluhan tentang asupan makanan yang baik salah satunya dengan menu gizi seimbang agar status gizi anak balita menjadi baik.

\section{Daftar Pustaka}

Adriani, M., \& Wirjatmadi, B. (2014). Peranan gizi dalam siklus kehidupan. Jakarta: Kencana Prenada Media Group, 2, 245-278.

Behrman, Kligman, Arvin, \& Wahab, S. (2016). Ilmu Kesehatan Anak Nelson (15th ed.). Jakarta: EGC.

Budiman, Riyanto, \& Agus. (2013). Kuesioner Pengetahuan dan Sikap dalam Penelitian Kesehatan. Salemba Medika.

Dewi, N. R., \& Rusjiyanto, S. K. M. (2018). Faktor-Faktor Yang Mempengaruhi Status Gizi Pada Anak Balita Di Instalasi Rawat Jalan RSUD Ir. Soekarno Kabupaten Sukoharjo. Universitas Muhammadiyah Surakarta.

Dinkes Kab Kuningan. (2019). Kasus gizi kurang di Kabupaten Kuningan pada tahun 2018.

Kementerian Kesehatan Republik Indonesia. (2018). Penilaian Status Gizi. Jakarta: Kementrian Kesehatan Republik Indonesia. 
JURNAL ILMU KESEHATAN BHAKTI HUSADA:

HEALTH SCIENCES JOURNAL, Vol. 11 No. 02, DESEMBER 2020

DOI: $10.34305 / j i k b h . v 11 \mathrm{i} 2.199$

Kementerian Kesehatan Republik Indonesia. (2018). Profil Kesehatan Indonesia Tahun 2017.

Linda, O., \& Hamal, D. K. (2016). Hubungan Pendidikan dan Pekerjaan Orangtua serta Pola Asuh dengan Status Gizi Balita di Kota dan Kabupaten Tangerang, Banten. Jurnal Kesehatan, 1, 34-41.

Melinda A. (2020). Miris Kabupaten Kuningan Termasuk Penyumbang Stunting Terbanyak.

Mubarak, W. I., Chayatin, N., \& Rozikin, S. (2017). Promosi kesehatan sebuah pengantar proses belajar mengajar dalam pendidikan. Yogyakarta: Graha Ilmu, 30 .

Notoatmodjo, S. (2017). Promosi kesehatan dan ilmu perilaku. Jakarta: Rineka Cipta, 20.

Novianto H. (2019). Angka Stinting Turun, Tapi Belum Standar WHO.

Par'I, H. M. (2016). Penilaian Status Gizi Dilengkapi Proses Asuhan Gizi Terstandar. EGC.

Rahmatillah, D. K. (2018). Hubungan Pengetahuan Sikap dan Tindakan terhadap Status Gizi. Amerta Nutrition, 2(1), 106-112.
Ciptaan disebarluaskan di bawah

Lisensi Creative Commons Atribusi-

NonKomersial-BerbagiSerupa 4.0

Internasional.

Romdiyatin, I. I. N. (2016). Hubungan Pengetahuan Gizi dengan Kebiasaan Jajan pada Anak Sekolah di SD Muhammadiyah Wedi Kabupaten Klaten Tahun 2001. Diponegoro University.

Say, L., Chou, D., Gemmill, A., Tunçalp, Ö., Moller, A.-B., Daniels, J., Gülmezoglu, A. M., Temmerman, M., \& Alkema, L. (2018). Global causes of maternal death: a WHO systematic analysis. The Lancet Global Health, 2(6), e323-e333.

Stastika. (2018). Negara Paling Terdampak Kelaparan dan Kekurangan Gizi. Sindonews.Com.

Suhardjo. (2013). Berbagai Cara Pendidikan Gizi (1st ed.). Yogyakarta: Bumi Aksara.

Susilowati, E., \& Himawati, A. (2017). Hubungan Tingkat Pengetahuan Ibu tentang Gizi Balita dengan Status Gizi Balita di Wilayah Kerja Puskesmas Gajah 1 Demak. Jurnal Kebidanan, 6(13), 21-25.

Syarifah, L., Mardjan, \& Budiastutik, I. (2014). Hubungan antara Pengetahuan dan Sikap Ibu dengan Kejadian Gizi Kurang pada Balita di Wilayah Kecamatan Pontianak Kota. Jurnal Mahasiswa Dan Peneliti Kesehatan, 16(2), 13-27. 